\title{
The Relationship between the Motivation for Physical Activity and Life Skills among Chinese and Japanese College Students
}

\author{
Yulong Chen ${ }^{*}$, Hironobu Tsuchiya² \\ ${ }^{1}$ Osaka University of Health and Sports Science Graduate School, Osaka, Japan \\ ${ }^{2}$ Osaka University of Health and Sports Science, Osaka, Japan \\ Email: *chenyulongg@gmail.com
}

How to cite this paper: Chen, Y. L., \& Tsuchiya, H. (2016). The Relationship between the Motivation for Physical Activity and Life Skills among Chinese and Japanese College Students. Advances in Physical Education, 6, 283-291.

http://dx.doi.org/10.4236/ape.2016.64029

Received: July 15, 2016

Accepted: September 23, 2016

Published: September 26, 2016

Copyright $\odot 2016$ by authors and Scientific Research Publishing Inc. This work is licensed under the Creative Commons Attribution International License (CC BY 4.0).

http://creativecommons.org/licenses/by/4.0/ (c) (i) Open Access

\begin{abstract}
Participation in physical activity is beneficial for health and motivation is an important theme in sport psychology. The purpose of this study was to examine the difference of the relationship between the motivation for physical activity and daily life skills among Chinese and Japanese college students. A questionnaire survey was conducted for 1039 college students (Chinese, $n=526$; Japanese, $n=513$ ). Japanese and Chinese version of Physical Activity and Leisure Motivation Scale (PALMS, 1, 2) and a Daily Life Skills Scale for College Students (DLS, 3, 4) were completed by the participants. The PALMS includes eight sub scales which are Mastery, Physical Condition, Affiliation, Psychological Condition, Appearance, Others' Expectations, Enjoyment and Competition/Ego. DLS includes 8 sub-scales, which are classified into 2 general skills: skills used mainly in personal situations (planning, knowledge summarization, self-esteem, and positive thinking), and skills used generally in interpersonal situations (intimacy, leadership, empathy, and interpersonal manner). The Chinese version of "Daily Life-Skills Scale" created in this study was confirmed, Significant differences between Chinese and Japanese University students were observed. Chinese college students had a higher mean score for the intimacy factor, leadership factor, planning factors, knowledge summarization factor and self-esteem factor. While Japanese college students had a higher mean scores for the aspects of empathy and interpersonal manner. This study found different relationships between the motivation for physical activity and daily life skills among Chinese and Japanese college students. It might be due to cultural differences between those countries. Future research should be focusing on gender and cultural differences of both countries regarding to the motivation for leisure.
\end{abstract}

\section{Keywords}

Chinese and Japanese University Students, PALMS, Life Skills 


\section{Introduction}

Shimamoto and Ishii (2006) developed a scale for evaluating "life skills" as one measure for early detection of students' problems and for deepening their self-understanding. Life skills are defined as, "behaviors that are necessary for effective living" (Jr. Brooks, 1984). Moreover, the World Health Organization (WHO) has defined life skills as "necessary skills to constructively and effectively manage various issues and needs arising in daily life". Life skills are general psychosocial skills that can be used to solve various problems (Kawabata, 1994). They are regarded as indices of development of students' personality that can be improved through repeating training (Shimamoto \& Ishii, 2007). Recently, young people's life skills have been focused in China, as well as in Western countries, as well as in Japan, because the decline in life skills, including social skills has become a social problem (Chen \& Tsuchiya, 2016). The study of life skills is an important issue in contemporary China.

Factors related to improvement of life skills have often been investigated in sports psychology. For example, Murakami et al. (2004), Ueno (2001) compared life skills between students belonging and those not belonging to sports clubs, and examined the effects of sports club activities on life skills. These studies have suggested that physical education and sports club activities have positive effects on life skills. However, correlations between university students' motives for participating in sports and their life skills in China and Japan have not been examined to date.

Chen and Tsuchiya (2016) conducted a comparative study of life skills between Chinese and Japanese university students. The results indicated that among life skills, "intimacy", "leadership", "planning", "knowledge summarization", and "self-esteem" were higher in Chinese students, whereas "empathy" and "interpersonal manners" were higher in Japanese students. Furthermore, it was indicated that students doing exercise more often had higher life skills (Chen \& Tsuchiya, 2016), suggesting that life skills are correlated with exercise. This study investigated correlations between university students' motives for participating in exercise and their life skills by comparing Chinese and Japanese students. The aim of the study was to contribute to university students' educational guidance in the two countries.

\section{Method}

\subsection{Participants and the Survey Period}

China is a multiethnic nation with various regional differences. Participants of this study were students at universities located in large cities, and most participants were Han Chinese. From March to April in 2014, a questionnaire survey was conducted with students $(\mathrm{N}=550)$ at three universities located in urban areas in China (A in Beijing, $B$ and $C$ in Haikou). The number of valid responses was 526, which included those from including 237 men and 289 women (mean age 19.35, \pm 0.48 years). A question-

naire consisting of identical question items was conducted with Japanese students ( $\mathrm{N}=$ $550)$ at three universities located in cities with a one million or higher population ( $D$ in 
Osaka, E in Nara, and F in Kyoto) from April to May in 2014. The number of valid responses was 513, which included 228 men and 285 women (mean age 18.35, \pm 0.5 years).

\subsection{Measures}

\subsubsection{Attributes of Participants}

Items on sex, age, exercise conditions, conditions of sports club affiliation (1) University clubs, 2) Fitness clubs, 3) Sports club teams outside the university, 4) Not belonging to any club) and exercise levels were identified. Moreover, items for measuring intensity of exercise were developed, requiring participants to choose one from three choices: low (they can sing during exercise), middle (they can talk but cannot sing during exercise), and high (they can just talk a few words when stopping to breathe).

\subsubsection{Life Skills}

Japanese students' life skills were measured using the "Daily Life Skills Scale for College Students" developed by Shimamoto and Ishii (2006), based on previous studies on life and social skills (Suzuki, 1992). This scale consists of eight sub-scales and 24 items. Participants are required to respond using a 4-point scale ranging from 1 (not at all) to 4 (very true), such that higher scores indicated higher skills. The eight types of skills were classified into individual and interpersonal skills, such that the former included "planning", "knowledge summarization", "self-esteem", and "positive thinking”. And the latter included "intimacy", "leadership", "empathy", and "interpersonal manners". Chinese students' life skills were assessed using the Chinese version of "Daily Life Skills Scale for College Students" developed by Chen and Tsuchiya (2016).

\subsubsection{Motives for Participating in Exercise}

Japanese students' motives for participating in exercise were assessed using the Japanese version of the Physical Activity and Leisure Motivation Scale (PALMS) developed by Machida et al. (2013). This scale consists of eight sub-scales and 40 items. Participants are required to respond using a five-point scale ranging from 1 (totally disagree) to 5 (strongly agree), such that higher scores indicated higher motivation for participating in exercise. The eight types of motives were as follows; "mastery", "physical conditions”, “affiliation”, “psychological conditions”, “appearance”, “others' expectations”, “enjoyment", and “competition/ego". Chinese students' motives were assessed using the Chinese version of PALMS developed by Wang et al. (2013).

\subsection{Procedures}

An anonymous questionnaire survey was conducted simultaneously in the two groups. Ethical aspects of the study were taken into consideration by obtaining the approval of all the participants before the study through the teachers' cooperation in each university. Questionnaires were distributed at the start of classes. Then, participants responded to the questionnaires immediately and they were collected. 


\section{Results}

\subsection{Mean Values, SD, and Results of a T-Test of Life Skills and Motives for Participating in Exercise in Chinese and Japanese University Students}

Table 1 shows the results of a t-test conducted on PALMS sub-scale scores: mastery, physical conditions, affiliation, psychological conditions, appearance, others' expectations, enjoyment, and competition/ego, as well and on Daily Life Skills Scale for College Students sub-scale scores: intimacy, leadership, planning, empathy, knowledge summarization, self-esteem, positive thinking, and interpersonal manners. Results indicated that scores of leadership, planning, knowledge summarization, self-esteem and competition/ego in Chinese students were higher compared to Japanese students. On the other hand, scores of empathy, physical condition, psychological conditions, and enjoyment were higher in Japanese students than in Chinese students.

\subsection{Effects of Motives for Participation in Exercise on Life Skills}

\subsubsection{Results of Correlation Analysis}

Table 2 shows correlation coefficients between motives for participating in exercise scores and life skills scores. The total motives for exercise participation scores had positive correlations with all the sub-scales of life skills, with the exception of positive

Table 1. Mean values, SD, and results of a t-test in Chinese and Japanese university students.

\begin{tabular}{ccccccc}
\hline & \multicolumn{2}{c}{ China $(\mathrm{n}=526)$} & \multicolumn{2}{c}{ Japan $(\mathrm{n}=513)$} & \multirow{2}{*}{-test } \\
\hline & Mean & S.D. & Mean & S.D. & \\
\hline Intimacy & 8.81 & 1.61 & 8.74 & 1.72 & 0.37 \\
Leadership & 8.09 & 1.68 & 7.23 & 1.95 & $9.02^{* * *}$ \\
Planning & 7.98 & 1.68 & 7.63 & 1.97 & $9.19^{* *}$ \\
Empathy & 8.31 & 1.65 & 8.93 & 1.66 & $6.47^{* * *}$ \\
Knowledge summarization & 8.56 & 1.57 & 7.5 & 1.83 & $8.44^{* * *}$ \\
Self-esteem & 7.95 & 1.73 & 7.20 & 1.98 & $7.84^{* * *}$ \\
Positive thinking & 8.20 & 1.40 & 8.16 & 1.51 & 0.23 \\
Interpersonal manners & 9.52 & 1.57 & 9.73 & 1.63 & 7.50 \\
Mastery & 17.40 & 3.68 & 17.57 & 3.47 & 0.26 \\
Physical conditions & 17.13 & 3.34 & 20.37 & 2.81 & $5.17^{* * *}$ \\
Affiliation & 15.89 & 3.43 & 16.34 & 3.42 & 2.6 \\
Psychological conditions & 16.00 & 3.47 & 18.95 & 3.02 & $9.71^{* * *}$ \\
Appearance & 16.51 & 3.67 & 16.78 & 3.76 & 0.43 \\
Others' expectations & 15.61 & 3.71 & 16.92 & 3.26 & 2.25 \\
Enjoyment & 15.58 & 3.30 & 19.00 & 3.12 & $4.63^{* * *}$ \\
Competition/ego & 15.65 & 3.48 & 12.32 & 3.47 & $5.71^{* * *}$ \\
\hline
\end{tabular}

${ }^{*} P<0.05,{ }^{* *} P<0.01,{ }^{* * *} P<0.001$. 
Table 2. Correlation coefficients among independent variables of exercise participation motives.

\begin{tabular}{|c|c|c|c|}
\hline & \multirow{3}{*}{ Skills } & China & Japan \\
\hline & & $(\mathrm{n}=526)$ & $(\mathrm{n}=513)$ \\
\hline & & Scale Score & Scale Score \\
\hline \multirow{4}{*}{ Individual skills } & Planning & $0.31^{\star *}$ & $0.32^{\star *}$ \\
\hline & Knowledge summarization & $0.37^{\star *}$ & $0.36^{* *}$ \\
\hline & Self-esteem & $0.35^{\star *}$ & $0.32^{\star *}$ \\
\hline & Positive thinking & $0.11^{\star *}$ & $0.12^{*}$ \\
\hline \multirow{4}{*}{ Interpersonal skills } & Intimacy & $0.28^{* *}$ & $0.41^{\star *}$ \\
\hline & Leadership & $0.36^{\star \star}$ & $0.39^{\star *}$ \\
\hline & Empathy & $0.25^{* *}$ & $0.36^{* *}$ \\
\hline & Interpersonal manners & $0.24^{* *}$ & $0.32^{\star *}$ \\
\hline
\end{tabular}

${ }^{*} P<0.05,{ }^{* *} P<0.01,{ }^{* * *} P<0.001$.

thinking, i.e. planning, knowledge summarization, self-esteem, intimacy, leadership, empathy, and interpersonal manners. Among individual life skills, planning, i.e. skills for efficiently dealing with different information, had a weak positive correlation with motives for participation in exercise. On the other hand, among interpersonal life skills, interpersonal manners, i.e. appropriate attitude towards superiors, and strangers, had a weak positive correlation with motives. The above results supported tendencies indicated by Shimamoto and Ishii (2007).

This study focused on the results of correlation analysis between Chinese and Japanese students. Subsequently, multiple regression analyses were conducted. In addition to planning, knowledge summarization, and self-esteem, the following four types of life skills were analyzed, in total seven types of life skills; intimacy, i.e. skills for developing and maintaining intimate relationships with friends, leadership, i.e. skills for positively being involved in activities within a group one belongs to, empathy, i.e. skills for empathizing with others' feelings based on one's own experience, and interpersonal manners, i.e. skills for making smooth relationships with others.

\subsubsection{Probability of Multicollinearity}

Correlation coefficients among independent variables of exercise participation motives were $0.513-0.684(P<0.001)$ in Chinese students and $0.347-0.584(P<0.001)$ in Japanese students. Correlation coefficients of 70 or higher were not observed. Furthermore, Oshio (2004) suggested that generally multicollinearity occurred when the value of VIF was 10 or higher. However, VIF values in the present study were $1.36-2.41$ for Chinese and $1.01-2.06$ for Japanese students. Therefore, the possibility of multicollinearity in multiple regression analysis was low.

\subsubsection{Results of Multiple Regression Analysis and Discussion}

Table 3 shows the results of multiple regression analysis with sub-scales of motives for exercise participation as independent variables and sub-scales of life skills as dependent 


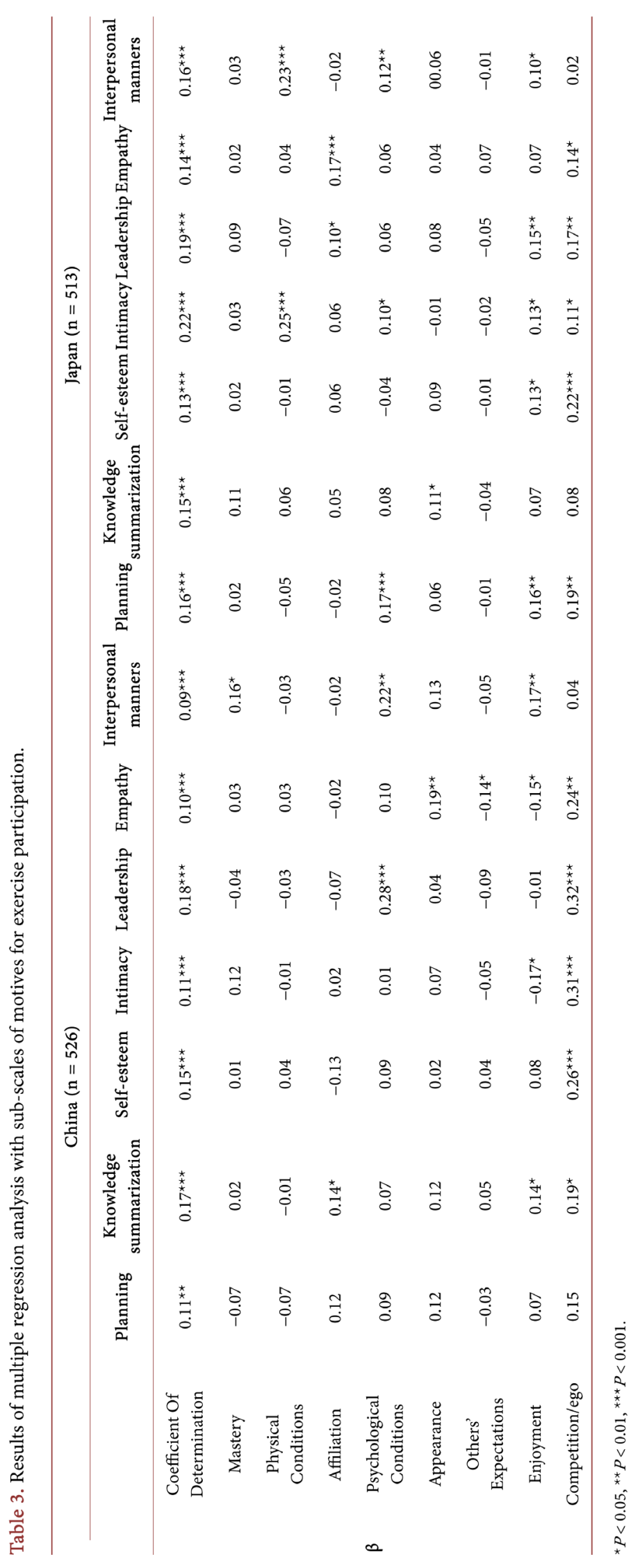


variables. Examining the coefficients of determination indicated that all indices were significant at the $1 \%$ level. It is suggested that motives for participating in exercise in daily life had a highly significant effect on the seven types of skills.

First, each standardized partial regression coefficient of each independent variable was examined in Chinese students, which indicated that each of the following variables affected each dependent variable: mastery, affiliation, psychological conditions, appearance, others' expectations, enjoyment and competition/ego $(\beta=-0.14-0.32, P<$ 0.001). Values between psychological conditions as well as competition/ego and subscales of life skills exceeded 0.20 , which indicated that that they were correlated. Concretely, the psychological condition had a positive effect on leadership, i.e. ability to summarize members' opinions in discussions and to lead other members in group activities $(\beta=0.28, P<0.001)$, and on interpersonal manners, i.e. being able to behave politely with superiors and use polite words with elderly $(\beta=0.22, P<0.01)$. It was suggested that people doing exercise with the aim of improving their mental conditions might have better leadership and interpersonal manners. Moreover, competition/ego had positive effects on self-esteem, i.e. love of oneself, and satisfaction with one's own life $(\beta=0.26, P<0.001)$, on intimacy, i.e. being able to consult with friends without hesitation when facing problems and asking friends for advice $(\beta=0.31, P<0.001)$, on empathy, i.e. wanting to help people in trouble, or feeling others' happiness as if it were one's own $(\beta=0.32, P<0.001)$, and on leadership $(\beta=0.24, P<0.01)$. These results suggested that people doing exercise motivated by competition/ego develop self-esteem, intimacy, empathy, and leadership.

Next, each standardized partial regression coefficient was examined for Japanese students. Among the eight independent variables, the following variables affected each dependent variable: physical condition, affiliation, psychological condition, appearance, enjoyment, and competition/ego $(\beta=-0.10-0.248, P<0.001)$. Values between psychological conditions as well as competition/ego and the sub-scales of life skills exceeded 0.02 , which indicated that they were correlated. Concretely, physical condition had positive effects on intimacy $(\beta=0.25, P<0.001)$ and interpersonal manners $(\beta=$ $0.23, P<0.001)$. It was suggested that people participating in exercise with the aim of improving their physical condition had higher intimacy and interpersonal manners. Moreover, competition/ego had a positive effect on self-esteem $(\beta=0.22, P<0.001)$. People doing exercise motivated by competition/ego might have higher self-esteem. Consequently, results of multiple regression analysis indicated that competition/ego had a significant effect on various life skills both in Chinese and Japanese students. Mastery had an effect only in Chinese students, whereas physical condition had an effect only in Japanese students. In general, motives for participating in exercise had positive effects on life skills.

On the other hand, ratios of the explained variance in life skills changes caused by motives for participation in exercise were $17.9 \%$ in Chinese students and $21.6 \%$ in Japanese students at most, which were not high enough to explain most of the changes. It is considered that motives for participating in exercise examined in this study might be 
a part of the factors affecting life skills. However, it was confirmed that these motives had positive effects on university students' life skills. Therefore, physical education conducted in universities could be considered an important measure for improving the life skills of students.

\section{Conclusion}

\section{Effects of Motives for Participating in Exercise on Life Skills in Chinese and Japanese Students}

This study examined effects of motives for participating in exercise on life skills in Chinese and Japanese students by using multiple regression analysis. The results indicated that all the motives had positive effects on life skills. In Chinese students, enjoyment, competition/ego, psychological conditions, appearance, and others' expectations affected intimacy, leadership, and empathy, which were considered social skills related to physical education. On the other hand, in Japan, physical conditions, psychological conditions, enjoyment, competition/ego, and affiliation affected these three types of life skills. Furthermore, self-esteem, which was considered to be strongly related to various problem behaviors observed in puberty, was affected by competition/ego in Chinese students, whereas it was affected by enjoyment and competition/ego in Japanese students.

It is known that sports experiences have positive effects on individual life skills. However, correlations between motives for participating in exercise in daily life and individual life skills have not been examined to date. Studies on sports and life skills are expected to motivate empirical researches with the aim of investigating correlations with practical programs. In the future, effects of exercise experiences in daily life on life skills should be investigated further.

\section{References}

Chen, Y. L., \& Tsuchiya, H. (2016). A Cross-National Study of Daily Life Skills between University Students in China and Japan: Development of a Chinese Version of the Daily Life Skills Scale. Journal of Japan Society of Sports Industry, 26, 1-12. http://dx.doi.org/10.5997/sposun.26.1 1

Jr. Brooks, D. K. (1984). A Life-Skill Staxonomy: Defining Elements of Effectiv Efunctioning Through the Use of Delphitechnique. Unpublished Doctoral Dissertation, Athens: University of Georgia.

Kawabata, T. (Trans.) (1994). World Health Organization World Life Skills Education. Tokyo: Taishukan-Shoten.

Machida, H. Y., Araki, K., \& Tsuchiya, H. (2013). A Preliminary Examination of the Relationship between Physical Activity Motivation and Self-Efficacy among Physical Activity Participants in Japan. Proceedings of the Abstracts of the ISSP 13th World Congress of Sport Psychology, 77-78.

Murakami K., Tokunaga, M., \& Hashimoto, K. (2004). The Relationship between Health-Related Life Skills and Sport Experience for Adolescents. Human Performance Measurement, 1, 1-14

Oshio, A. (2004). Psychological Research Data Analysis by SPSS and Amos. Tokyo: TokyoTosho, 89-104.

Shimamoto, K., \& Ishii, M. (2006). Influence of Sport Experience in Physical Education Classes 
on Life Skills Acqui Sition between Athlete and Non-Athlete Students. Japanese Journal of Sport Psychology, 54, 211-221.

Shimamoto, K., \& Ishii, M. (2007). A Study of Influence on Life Skills of Sport Experience in Physical Education Classes in College Students. Japanese Journal of Sport Psychology, 34, 1-11.

Suzuki, T. (1992). Some Factors Influencing Prosocial Behavior: Empathy, Social Skill and Extraversion. The Japanese Group Dynamics Association, 32, 71-84.

http://dx.doi.org/10.2130/jiesp.32.71

Ueno, K. (2001). Effect of Participation in High School Athletic Club Activities for Acquisition of Life Skills on Students' Career Maturity. Japanese Association of Educational Psychology, 34, 13-22.

Wang, J., Morris, T., Khoo, S., Hu, W. F., \& Tang, Y. P. (2013). Psychometric Validation of the physical Activity and Leisure Motivation Scale (PALMS) in a Chinese Sample. Proceedings of the Abstracts of the ISSP13th World Congress of Sport Psychology, 293-294.

Submit or recommend next manuscript to SCIRP and we will provide best service for you:

Accepting pre-submission inquiries through Email, Facebook, LinkedIn, Twitter, etc. A wide selection of journals (inclusive of 9 subjects, more than 200 journals)

Providing 24-hour high-quality service

User-friendly online submission system

Fair and swift peer-review system

Efficient typesetting and proofreading procedure

Display of the result of downloads and visits, as well as the number of cited articles

Maximum dissemination of your research work

Submit your manuscript at: http://papersubmission.scirp.org/

Or contact ape@scirp.org 